\title{
Can a Torque Teno Virus (TTV) Be a Naked DNA Particle Without a Virion Structure?
}

\author{
Perumal Arumugam Desingu ${ }^{1 *}$, Kumaresan Nagarajan ${ }^{2 *}$ and Kuldeep Dhama ${ }^{3 *}$ \\ ${ }^{1}$ Department of Microbiology and Cell Biology, Indian Institute of Science, Bengaluru, India, ${ }^{2}$ Department of Veterinary \\ Pathology, Madras Veterinary College, Veterinary and Animal Sciences University (TANUVAS), Chennai, India, ${ }^{3}$ Avian \\ Diseases Section, Division of Pathology, ICAR-Indian Veterinary Research Institute (IVRI), Bareilly, India
}

Keywords: torque teno virus (TTV), Anelloviridae, without capsid, without virion structure, DNA particle (DNAp)

\section{INTRODUCTION}

OPEN ACCESS

Edited by:

Bernard La Scola,

Aix-Marseille Université, France

Reviewed by:

Daniele Focosi,

Pisana University Hospital, Italy

Rodrigo Araújo Lima Rodrigues,

Federal University of Minas

Gerais, Brazil

*Correspondence:

Perumal Arumugam Desingu perumald@iisc.ac.in; padesingu@gmail.com

Kumaresan Nagarajan

nagavet@gmail.com

Kuldeep Dhama

kdhama@rediffmail.com

Specialty section:

This article was submitted to

Fundamental Virology,

a section of the journal

Frontiers in Virology

Received: 24 November 2021

Accepted: 13 January 2022

Published: 25 February 2022

Citation:

Desingu PA, Nagarajan K and Dhama K (2022) Can a Torque Teno

Virus (TTV) Be a Naked DNA Particle

Without a Virion Structure?

Front. Virol. 2:821298.

doi: 10.3389/fviro.2022.821298
Torque teno virus (TTV) is a single-stranded, circular DNA virus, named after a patient (TT), formerly known as transfusion-transmitted virus (TTV), and the naming was just an accidental coincidence. The first TTV genome was detected by Nishizawa et al. in human serum (1). Due to the presence of TTV DNA in the fraction of $1.26 \mathrm{~g} / \mathrm{cm}^{3}$ at the sucrose density gradient, DNase I did not digest this; therefore, it was considered a virus (1). Subsequently, numerous TTV and TTVrelated genomes were detected in humans and animals (2-4). According to the ICTV 2020 report, the Anelloviridae family contains 31 genera and 155 species. Among these 31 genera, the genus Alphatorquevirus has 26 species; other genera include Betatorquevirus (TTMV [torque teno mini virus] with 38 species) and Gammatorquevirus (TTMDV [torque teno midi virus] with 15 species), which contain TTV that could infect most humans. The TTV infects almost all humans globally with a high prevalence rate/omnipresence (2-5), co-infection of different genotypes of TTVs in an individual is also documented $(6,7)$, and it could persist in the infected individual for a long time (8). Furthermore, the TTV DNA has been detected in blood, semen, breast milk, saliva, nasal secretions, tears, bile, urine, and feces (3-5). The TTV is likely to transmit through blood, semen, breast milk, saliva, and feces (9-12). Next, the TTV DNA levels in the blood are considered a potential marker for immunological status in solid organ transplantation and immunosuppression drug treatment (13-15). The correlation of TTV DNA levels in pathological conditions like hepatitis, gastroenteritis, periodontitis, multiple sclerosis, and cancer was also documented (16-19). However, the specific pathogenesis of TTV has not been fully established, and it is also believed that it may be a virus that benefits humans (5). Interestingly, the TTV genome in the water is considered an indicator of viral contamination due to its high prevalence in water bodies $(20,21)$.

\section{ATTEMPT TO VISUALIZE TTV ON ELECTRON MICROSCOPES}

Only two attempts have been made to show TTV on electron microscopes so far. HIV-infected patients with a TTV DNA titer of $10^{8}$ copies $/ \mathrm{ml}$ in the serum samples were used in the first attempt. TTV DNA-rich fractions of $1.31-1.33 \mathrm{~g} / \mathrm{cm}^{3}$ were subjected to electron microscopy and visualized as spherical, virus-like structures with a diameter of 30-32 nm (9). Next, to increase the specificity, immunogold electron microscope analysis for the TTV-positive serum samples was conducted using gold-labeled goat anti-human IgG to demonstrate the TTV (9). For fecal specimens, fractions of human plasma $\gamma$-globulin with or without antibodies against TTV were used to prove the virus structure in immunogold electron microscope analysis (9). Although immunogold electron microscope analysis showed possible TTV particles in serum and fecal samples, 
some questions remain unanswered. This raises the question of whether the serum fractions of an HIV-infected patient contain only TTV viruses at $1.31-1.33 \mathrm{~g} / \mathrm{cm}^{3}$ with $30-32 \mathrm{~nm}$ size and whether there are only TTV antibodies in human serum in this condition. Also, some other viruses with $30-32 \mathrm{~nm}$ in the stool sample and their antibodies may have been present in the serum. However, the authors also discussed visualizing probable TTV particles in serum samples and fecal supernatant. Furthermore, they recommended developing a culture system capable of supporting the productive infection of TTV (9). In the second attempt, the TTV-like electron microscopic structure in the cell culture model was demonstrated by the transformation of TTV molecular clones (22). Furthermore, the viral TTV DNA yield was reduced in the subsequent passage of this cell culture supernatant in the TTV molecular clones-based studies (23). However, the authors mentioned the electron microscopic structure as a TTV-like particle (22). Overall, TTV's electron microscopic structure has not yet appeared at the most precise level of hard work and standardization. This raises the question of whether TTV can create a virion structure.

\section{ATTEMPT TO ISOLATE INFECTIOUS TTV}

Several research groups attempted to isolate the virus from clinical samples in the cell culture system. The replication of the TTV in liver cells (24) and bone marrow cells (BMCs) collected from clinical specimens (25) was documented. Furthermore, upon stimulation, the replication and release of the TTV in peripheral blood mononuclear cells (PBMCs) collected from clinical samples have been established in the cell culture system (26). The reinfectious nature of supernatants collected from infected PBMCs in healthy PBMCs was also documented (26). However, this infectious nature has only been shown on a single passage level. It has also been observed that TTV in the serum infects the Chang liver and Raji cell lines, thereby releasing TTV DNA into the supernatant (27). But they used infected liver cells for serial passage, and assays using Raji cells showed reinfection in only one passage on cell lines (27). TTV replication did not cooperate best with primary cells at expected levels, so TTV molecular clones were used to conduct molecular and cell biological studies (28). Furthermore, different studies tried to obtain the infectious virus by constructing a full-length TTV clone of different TTV genotypes in several cells and varieties of conditions (22, 23, 29-31). These studies reported successful transfection of the TTV molecular clones and confirmed TTV replication and TTV DNA release in the supernatant. Unfortunately, they could not come up with the infectious virus progeny to infect the healthy cells in continuous passaging $(22,23,29-31)$. A few studies have shown that TTV DNA levels decrease with each subsequent passage $(23,29)$, and some studies have not reported a description of the sequence of successive passages $(30,31)$. Despite more than 20 years of hard work and the efforts of many research groups to isolate infectious TTV from various cells, it is evident that no one has yet been able to isolate infectious TTV and that no one has demonstrated a scientifically proven electron microscope structure. Some research groups have published what they have tried. But we hope that hundreds of researchers have stopped this study at the stage of DNA detection and sequencing due to the inability to isolate the virus. Similarly, we believe that most TTV pathology studies focus on correlation studies due to a lack of virus isolation. All of these raise the great debate of whether TTV can form the virion structure or whether they are just TTV DNA molecules.

\section{TTV DNA WITHIN THE EXOSOMES}

On the other hand, recently, it has been reported that TTV DNA is present in human plasma exosomes (32). Though the electron microscopic structure resembling a TTV-like size inside the exosomes was also demonstrated, the authors are unsure whether it is the TTV particle or any other particles (32). However, it has been scientifically proven that exosomes contain TTV DNA and are not affected by DNAse treatment (32). Furthermore, exosomes have also been found in sucrose density gradients that are almost identical to the sucrose density gradients in which TTV's DNA was detected (33-35). It is well known that the DNA inside the exosomes cannot be digested by DNases $(36,37)$. Interestingly, both the exosomes and TTV genomes share a common biological environment: blood, semen, breast milk, saliva, nasal secretions, tears, bile, urine, and feces $(34,35)$. TTV DNA is called a virus because of its presence in a virus-specific sucrose density and because it is not digestible by DNases (1). From these, the question arises as to whether the DNA of TTV is still believed to be a virus because the DNA of TTV within the exosomes is also at a sucrose density gradient and DNases do not digest it.

\section{POSSIBILITIES FOR TTV TO BE A NAKED DNA PARTICLE}

The following is a list of possibilities for TTV to be a naked DNA particle that does not have a virion structure or cannot produce a virus structure protein. (i) So far, no one has successfully demonstrated the virion structure of TTV on electron microscopy with strong proven evidence. (ii) Although TTV is found in almost all humans and is ubiquitous, no one has yet been able to isolate a continuous infective virus progeny. (iii) It was also believed that the virus contained structural protein because DNases could not digest from a virus-specific sucrose density gradient. At the same time, the TTV DNA inside the exosomes at the virus-specific sucrose density gradient may not have been digested by the DNases. (iv) Direct clinical samples of BMCs and stimulated PBMCs have been shown to replicate TTV and release TTV DNA. Still, there is no evidence to isolate a continuous, infectious virus progeny. (v) The TTV in the clinical serum samples can also be shown to infect cell lines and release the TTV DNA, which is well documented. Still, there is no evidence to isolate a cell-free virus progeny to infect several subsequent passages. (v) TTV molecular clone-based transfection showed 
successful replication within cells and the release of TTV DNA into the supernatant. However, the subsequent viral DNA load was reduced from passage to passage. From all of the above, it is well established that TTV replicates in infected human cells and releases TTV DNA. Yet, the question of the release of the infectious virion with the virus structure protein remains unanswered.

Overall, we believe that TTV is likely to be a naked DNA particle that cannot produce viral structure protein. TTV may be a virus that cannot make capsids, such as the recently classified families Endornaviridae (38), Hypoviridae (39), and Narnaviridae (40) viruses, or it may be like the Amalgaviridae virus that is capable of encrypting the capsid gene but not capable of producing virions $(40,41)$. The putative capsid protein of Amalgaviridae viruses with double-stranded (ds) RNA genomes is homologous with the nucleocapsid protein of negative-stranded RNA viruses of the genera Phlebovirus (Bunyaviridae) and Tenuivirus (41). However, it has been reported that Amalgaviridae viruses cannot produce virions (40, 41). Similarly, since the ORF1 N-terminal of TTV has argininerich regions similar to the capsid proteins of circoviruses viruses, it is believed that the ORF1 protein of TTV may be the capsid protein $(5,42)$. It is noted that the replication-competent circular DNA (rccDNA) includes the bovine meat and milk factors (BMMF) and sphinx infective DNA molecules and that capsid proteins do not form fully mature viral structural proteins and only remain as infective and replicative circular ssDNA molecules (43-45). Capsid protein (virion) in viruses acts as a physical barrier to protect the virus genome, recognizes the host cell receptors and entry, causes systemic infections in the host, and facilitates transmission (40). Interestingly, the viruses without capsid (virion) such as the Endornaviridae, Hypoviridae, Narnaviridae, and Amalgaviridae families of viruses are transmitted through pollen grains, gametes, seeds, spores, and hyphal anastomosis, and they are often not associated with a significant pathological condition; furthermore, they can persist for a long time in the host $(38,39,46)$. However, the cell-free transmission of these viruses is not fully established $(38,39,46)$. Similarly, TTV is also present globally with a high prevalence rate, co-infection of multiple genotypes in an individual occurs, and the virus persists in an individual for a long time $(2-4,6,8)$. Moreover, the cell-free transmission of TTV has also not yet been proved. However, TTV-infected cell culture supernatant has been shown to establish infection for very few serial passages $(23,26,27,29)$. From these findings, it can be inferred that TTV may have established infection through exosomes in the cell culture supernatant. Although the molecular mechanisms have not been fully identified, the potential for DNA viruses such as herpes simplex type 1, human herpesvirus 6, Epstein-Barr virus (EBV), and Kaposi's sarcomaassociated herpesvirus (47); adenovirus (48); and RNA viruses such as hepatitis C virus (49), dengue virus (50), Zika virus (51), Seneca valley virus (52), and respiratory syncytial virus (53), to become intercellularly transmitted/spread through exosomes has been established. It has also been found that the rice dwarf virus (54), tick-borne Langat virus (55), and dengue virus (56) are transmitted from insects to plant phloem/human cells through the exosomes of insects. Since TTV DNA is present in human plasma exosomes (32), it is speculated that TTV may be able to spread intercellularly through these exosomes and that it may be transmitted from one human to another through these exosomes during blood transfusion. However, in-depth future studies are needed to prove the exosomesmediated spread/transmission of TTV. The fact that TTV can express virus-specific proteins (57-60) and that antibodies against the virus-specific proteins expressed are detected in the human serum $(57,59,61-63)$ confirms that TTV is a foreign material (virus). Since the detection of TTV's DNA in biological specimens such as serum $(9,64-67)$, saliva $(64,66,67)$, umbilical cord blood $(64,65)$, breast milk $(64,65)$, semen (66), feces (9), and nasal secretions (11), it can be assumed that TTV is transmitted through these biological specimens, although the extent to which biological specimens can cause infections is not widely known.

\section{CONCLUSION}

In conclusion, it can be inferred that TTV may be a naked DNA particle without a virion structure, although further research is needed to establish this hypothesis. It is also likely to be a plasmid-like structure within human cells because humanspecific TTV only affects humans, and almost all humans are positive to it, regardless of age, gender, pathology/physiological status, geographical location, and season. Only the TTV DNA load in the serum fluctuates under different pathological conditions. It is imperative to determine how TTV spreads within the host and whether exosomes play a role in this spread. We also need to look at how TTV is transmitted from one person to another and whether there is functional importance of the live infected cell or exosome or cell-free TTV/TTV DNA for this transmission. It is imperative to determine how this live infected cell or exosome or cell-free TTV/TTV DNA recognizes the host cell and how it enters the cell. Can TTV DNA in exosomes be isolated from clinical samples and infect cell lines? If so, we need to scrutinize what kind of exosomes are and from what cell types the exosomes come from. When transfecting intact TTV DNA extracted from clinical samples, it is necessary to examine whether it successfully replicates and releases TTV DNA and in what cells it occurs and under what conditions. The importance of TTV in the direction of naked DNA or naked DNA within the exosomes needs to be explored to understand whether TTV has a beneficial or adverse effect on the host in cancer, organ transplantation, immunosuppression, and other pathological conditions.

\section{AUTHOR CONTRIBUTIONS}

$\mathrm{PD}, \mathrm{KN}$, and $\mathrm{KD}$ wrote the first draft of the manuscript, conceived the study, and wrote the final version of the manuscript. All authors contributed to the article and approved the submitted version. 


\section{FUNDING}

PD is a DST-INSPIRE faculty and is supported by research funding from the Department of Science and Technology,

\section{REFERENCES}

1. Nishizawa T, Okamoto H, Konishi K, Yoshizawa H, Miyakawa Y, Mayumi M. A novel DNA virus (TTV) associated with elevated transaminase levels in posttransfusion hepatitis of unknown etiology. Biochem Biophys Res Commun. (1997) 241:92-7. doi: 10.1006/bbrc.1997.7765

2. Sarairah H, Bdour S, Gharaibeh W. The Molecular Epidemiology and Phylogeny of Torque Teno Virus (TTV) in Jordan. Viruses. (2020) 12:20. doi: 10.3390/v12020165

3. Spandole S, Cimponeriu D, Berca LM, Mihaescu G. Human anelloviruses: an update of molecular, epidemiological and clinical aspects. Arch Virol. (2015) 160:893-908. doi: 10.1007/s00705-015-2363-9

4. Reshetnyak VI, Maev IV, Burmistrov AI, Chekmazov IA, Karlovich TI. Torque teno virus in liver diseases: on the way towards unity of view. World J Gastroenterol. (2020) 26:1691-707. doi: 10.3748/wjg.v26.i15.1691

5. Kaczorowska J, van der Hoek L. Human anelloviruses: diverse, omnipresent and commensal members of the virome. FEMS Microbiol Rev. (2020) 44:30513. doi: 10.1093/femsre/fuaa007

6. Niel C, Saback FL, Lampe E. Coinfection with multiple TT virus strains belonging to different genotypes is a common event in healthy Brazilian adults. J Clin Microbiol. (2000) 38:1926-30. doi: 10.1128/JCM.38.5.1926-1930.2000

7. Virgin HW, Wherry EJ, Ahmed R. Redefining chronic viral infection. Cell. (2009) 138:30-50. doi: 10.1016/j.cell.2009.06.036

8. Bedarida S, Dussol B, Signoli M, Biagini P. Analysis of Anelloviridae sequences characterized from serial human and animal biological samples. Infect Genetics Evol J Mol Epidemiol Evol Gene Infect Dis. (2017) 53:8993. doi: 10.1016/j.meegid.2017.05.017

9. Itoh Y, Takahashi M, Fukuda M, Shibayama T, Ishikawa T, Tsuda F, et al. Visualization of TT virus particles recovered from the sera and feces of infected humans. Biochem Biophys Res Commun. (2000) 279:71824. doi: 10.1006/bbrc. 2000.4013

10. McCann A, Ryan FJ, Stockdale SR, Dalmasso M, Blake T, Ryan CA, et al. Viromes of one year old infants reveal the impact of birth mode on microbiome diversity. PeerJ. (2018) 6:e4694. doi: 10.7717/peerj.4694

11. Maggi F, Pifferi M, Fornai C, Andreoli E, Tempestini E, Vatteroni M, et al. TT virus in the nasal secretions of children with acute respiratory diseases: relations to viremia and disease severity. J Virol. (2003) 77:241825. doi: 10.1128/JVI.77.4.2418-2425.2003

12. Kapusinszky B, Minor P, Delwart E. Nearly constant shedding of diverse enteric viruses by two healthy infants. J Clin Microbiol. (2012) 50:342734. doi: 10.1128/JCM.01589-12

13. Rezahosseini O, Drabe CH, Sorensen SS, Rasmussen A, Perch M, Ostrowski $\mathrm{SR}$, et al. Torque-Teno virus viral load as a potential endogenous marker of immune function in solid organ transplantation. Transplant Rev. (2019) 33:137-44. doi: 10.1016/j.trre.2019.03.004

14. Kotton $\mathrm{CN}$. Torque teno virus: predictor of infection after solid organ transplant? J Infect Dis. (2018) 218:1185-7. doi: 10.1093/infdis/jiy384

15. Burra P, Masier A, Boldrin C, Calistri A, Andreoli E, Senzolo M, et al. Torque Teno Virus: any pathological role in liver transplanted patients? Transplan Int Offic J Euro Soc Organ Transplant. (2008) 21:9729. doi: 10.1111/j.1432-2277.2008.00714.x

16. Magu SK, Kalghatgi AT, Bhagat MR. Incidence and clinical implication of TT virus in patients with hepatitis and its frequency in blood donors in India. Med J Armed Forces India. (2015) 71:340-4. doi: 10.1016/j.mjafi.2015. 06.023

17. Pinho-Nascimento CA, Leite JP, Niel C, Diniz-Mendes L. Torque teno virus in fecal samples of patients with gastroenteritis: prevalence, genogroups distribution, and viral load. J Med Virol. (2011) 83:1107-11. doi: 10.1002/jmv.22024
Government of India (DST/INSPIRE/04/2016/001067) and by a Core grant from the Science and Engineering Research Board (SERB), Department of Science and Technology (DST), Government of India (CRG/2018/002192).

18. Zhang Y, Li F, Shan TL, Deng X, Delwart E, Feng XP. A novel species of torque teno mini virus (TTMV) in gingival tissue from chronic periodontitis patients. Sci Rep. (2016) 6:26739. doi: 10.1038/srep26739

19. Sawata T, Bando M, Nakayama M, Mato N, Yamasawa H, Takahashi M, et al. Clinical significance of changes in Torque teno virus DNA titer after chemotherapy in patients with primary lung cancer. Respir Investig. (2018) 56:173-8. doi: 10.1016/j.resinv.2017.12.004

20. Griffin JS, Plummer JD, Long SC. Torque teno virus: an improved indicator for viral pathogens in drinking waters. Virol J. (2008) 5:112. doi: 10.1186/1743-422X-5-112

21. Diniz-Mendes L, Paula VS, Luz SL, Niel C. High prevalence of human Torque teno virus in streams crossing the city of Manaus, Brazilian Amazon. J Appl Microbiol. (2008) 105:51-8. doi: 10.1111/j.1365-2672.2007.03720.x

22. Leppik L, Gunst K, Lehtinen M, Dillner J, Streker K, de Villiers EM. In vivo and in vitro intragenomic rearrangement of TT viruses. J Virol. (2007) 81:9346-56. doi: 10.1128/JVI.00781-07

23. de Villiers EM, Borkosky SS, Kimmel R, Gunst K, Fei JW. The diversity of torque teno viruses: in vitro replication leads to the formation of additional replication-competent subviral molecules. J Virol. (2011) 85:728495. doi: 10.1128/JVI.02472-10

24. Okamoto H, Ukita M, Nishizawa T, Kishimoto J, Hoshi Y, Mizuo H, et al. Circular double-stranded forms of TT virus DNA in the liver. J Virol. (2000) 74:5161-7. doi: 10.1128/JVI.74.11.5161-5167.2000

25. Okamoto H, Takahashi M, Nishizawa T, Tawara A, Sugai Y, Sai T, et al. Replicative forms of TT virus DNA in bone marrow cells. Biochem Biophys Res Commun. (2000) 270:657-62. doi: 10.1006/bbrc.2000.2481

26. Mariscal LF, Lopez-Alcorocho JM, Rodriguez-Inigo E, Ortiz-Movilla N, de Lucas S, Bartolome J, et al. TT virus replicates in stimulated but not in non-stimulated peripheral blood mononuclear cells. Virology. (2002) 301:1219. doi: 10.1006/viro.2002.1545

27. Desai M, Pal R, Deshmukh R, Banker D. Replication of TT virus in hepatocyte and leucocyte cell lines. J Med Virol. (2005) 77:136-43. doi: 10.1002/jmv.20426

28. Kamahora T, Hino S, Miyata H. Three spliced mRNAs of TT virus transcribed from a plasmid containing the entire genome in COS1 cells. J Virol. (2000) 74:9980-6. doi: 10.1128/JVI.74.21.9980-9986.2000

29. Kakkola L, Tommiska J, Boele LC, Miettinen S, Blom T, Kekarainen T, et al. Construction and biological activity of a full-length molecular clone of human Torque teno virus (TTV) genotype 6. FEBS J. (2007) 274:471930. doi: 10.1111/j.1742-4658.2007.06020.x

30. Galmes J, Li Y, Rajoharison A, Ren L, Dollet S, Richard N, et al. Potential implication of new torque teno mini viruses in parapneumonic empyema in children. Eur Respir J. (2013) 42:470-9. doi: 10.1183/09031936.00107212

31. Borkosky SS, Whitley C, Kopp-Schneider A, zur Hausen H, de Villiers M. Epstein-Barr virus stimulates torque teno virus replication: a possible relationship to multiple sclerosis. PloS ONE. (2012) 7:e32160. doi: 10.1371/journal.pone.0032160

32. Martelli F, Macera L, Spezia PG, Medici C, Pistello M, Guasti $\mathrm{D}$, et al. Torquetenovirus detection in exosomes enriched vesicles circulating in human plasma samples. Virol J. (2018) 15:145. doi: 10.1186/s12985-018-1055-y

33. Fitzner D, Schnaars M, van Rossum D, Krishnamoorthy G, Dibaj P, Bakhti $\mathrm{M}$, et al. Selective transfer of exosomes from oligodendrocytes to microglia by macropinocytosis. J Cell Sci. (2011) 124:447-58. doi: 10.1242/jcs.074088

34. Brennan K, Martin K, FitzGerald SP, O’Sullivan J, Wu Y, Blanco A, et al. A comparison of methods for the isolation and separation of extracellular vesicles from protein and lipid particles in human serum. Sci Rep. (2020) 10:1039. doi: 10.1038/s41598-020-57497-7

35. Sidhom K, Obi PO, Saleem A. A review of exosomal isolation methods: is size exclusion chromatography the best option? Int J Mol Sci. (2020) 21:23. doi: 10.20944/preprints202007.0485.v2 
36. Thakur BK, Zhang H, Becker A, Matei I, Huang Y, Costa-Silva B, et al. Doublestranded DNA in exosomes: a novel biomarker in cancer detection. Cell Res. (2014) 24:766-9. doi: 10.1038/cr.2014.44

37. Torralba D, Baixauli F, Villarroya-Beltri C, Fernandez-Delgado I, LatorrePellicer A, Acin-Perez R, et al. Priming of dendritic cells by DNA-containing extracellular vesicles from activated $\mathrm{T}$ cells through antigen-driven contacts. Nat Commun. (2018) 9:2658. doi: 10.1038/s41467-018-05077-9

38. Valverde RA, Khalifa ME, Okada R, Fukuhara T, Sabanadzovic S, Ictv Report C. ICTV virus taxonomy profile: endornaviridae. J Gen Virol. (2019) 100:1204-5. doi: 10.1099/jgv.0.001277

39. Suzuki N, Ghabrial SA, Kim KH, Pearson M, Marzano SL, Yaegashi H, et al. ICTV Virus taxonomy profile: hypoviridae. J Gen Virol. (2018) 99:6156. doi: 10.1099/jgv.0.001055

40. Fermin G. Virion structure, genome organization, and taxonomy of viruses. Viruses. (2018) 18:17-54. doi: 10.1016/B978-0-12-811257-1.00002-4

41. Krupovic M, Dolja VV, Koonin EV. Plant viruses of the Amalgaviridae family evolved via recombination between viruses with doublestranded and negative-strand RNA genomes. Biol Direct. (2015) 10:12. doi: 10.1186/s13062-015-0047-8

42. Jazaeri Farsani SM, Jebbink MF, Deijs M, Canuti M, van Dort KA, Bakker $\mathrm{M}$, et al. Identification of a new genotype of Torque Teno Mini virus. Virol J. (2013) 10:323. doi: 10.1186/1743-422X-10-323

43. Whitley C, Gunst K, Muller H, Funk M, Zur Hausen H, de Villiers EM. Novel replication-competent circular DNA molecules from healthy cattle serum and milk and multiple sclerosis-affected human brain tissue. Genome Announc. (2014) 2:14. doi: 10.1128/genomeA.00849-14

44. de Villiers EM, Gunst K, Chakraborty D, Ernst C, Bund T, Zur Hausen H. A specific class of infectious agents isolated from bovine serum and dairy products and peritumoral colon cancer tissue. Emerging Microbes Infect. (2019) 8:1205-18. doi: 10.1080/22221751.2019.1651620

45. Eilebrecht S, Hotz-Wagenblatt A, Sarachaga V, Burk A, Falida K, Chakraborty D, et al. Expression and replication of virus-like circular DNA in human cells. Sci Rep. (2018) 8:2851. doi: 10.1038/s41598-018-21317-w

46. Zhan B, Cao M, Wang K, Wang X, Zhou X. Detection and characterization of cucumis melo cryptic virus, cucumis melo amalgavirus 1 , and melon necrotic spot virus in cucumis melo. Viruses. (2019) 11:81. doi: 10.3390/v11010081

47. Bello-Morales R, Ripa I, Lopez-Guerrero JA. Extracellular vesicles in viral spread and antiviral response. Viruses. (2020) 12:623. doi: 10.3390/v12060623

48. Crenshaw BJ, Gu L, Sims B, Matthews QL. Exosome biogenesis and biological function in response to viral infections. Open Virol J. (2018) 12:13448. doi: 10.2174/1874357901812010134

49. Ramakrishnaiah, V., Thumann, C., Fofana, I., Habersetzer, F., Pan, Q., de Ruiter, P. E., et al. (2013). Exosome-mediated transmission of hepatitis C virus between human hepatoma Huh7.5 cells. Proceed Nat Acad Sci USA 110:13109-113. doi: 10.1073/pnas.1221899110

50. Reyes-Ruiz JM, Osuna-Ramos JF, De Jesus-Gonzalez LA, Hurtado-Monzon AM, Farfan-Morales CN, Cervantes-Salazar $\mathrm{M}$, et al. Isolation and characterization of exosomes released from mosquito cells infected with dengue virus. Virus Res. (2019) 266:1-14. doi: 10.1016/j.virusres.2019.03.015

51. Zhou W, Woodson M, Sherman MB, Neelakanta G, Sultana H. Exosomes mediate Zika virus transmission through SMPD3 neutral Sphingomyelinase in cortical neurons. Emerg Microb Infect. (2019) 8:307-26. doi: 10.1080/22221751.2019.1578188

52. Xu G, Xu S, Shi $\mathrm{X}$, Shen $\mathrm{C}$, Hao J, Yan $\mathrm{M}$, et al. Intercellular transmission of Seneca Valley virus mediated by exosomes. Vet Res. (2020) 51:91. doi: 10.1186/s13567-020-00812-x

53. Chahar HS, Corsello T, Kudlicki AS, Komaravelli N, Casola A. Respiratory syncytial virus infection changes cargo composition of exosome released from airway epithelial cells. Sci Rep. (2018) 8:387. doi: 10.1038/s41598-017-18672-5

54. Chen Q, Liu Y, Ren J, Zhong P, Chen M, Jia D, et al. Exosomes mediate horizontal transmission of viral pathogens from insect vectors to plant phloem. Elife. (2021) 10. doi: 10.7554/eLife.64603.sa2

55. Zhou W, Woodson M, Neupane B, Bai F, Sherman MB, Choi KH, et al. Exosomes serve as novel modes of tick-borne flavivirus transmission from arthropod to human cells and facilitates dissemination of viral
RNA and proteins to the vertebrate neuronal cells. PLoS Pathog. (2018) 14:e1006764. doi: 10.1371/journal.ppat.1006764

56. Vora A, Zhou W, Londono-Renteria B, Woodson M, Sherman MB, Colpitts TM, et al. Arthropod EVs mediate dengue virus transmission through interaction with a tetraspanin domain containing glycoprotein Tsp29Fb. Proc Natl Acad Sci U S A. (2018) 115:E6604-13. doi: 10.1073/pnas.1720125115

57. Kakkola L, Bonden H, Hedman L, Kivi N, Moisala S, Julin J, et al. Expression of all six human Torque teno virus (TTV) proteins in bacteria and in insect cells, and analysis of their IgG responses. Virology. (2008) 382:1829. doi: 10.1016/j.virol.2008.09.012

58. Qiu J, Kakkola L, Cheng F, Ye C, Soderlund-Venermo M, Hedman $\mathrm{K}$, et al. Human circovirus TT virus genotype 6 expresses six proteins following transfection of a full-length clone. J Virol. (2005) 79:650510. doi: 10.1128/JVI.79.10.6505-6510.2005

59. Kakkola L, Hedman K, Vanrobaeys H, Hedman L, Soderlund-Venermo M. Cloning and sequencing of TT virus genotype 6 and expression of antigenic open reading frame 2 proteins. J Gen Virol. (2002) 83:97990. doi: 10.1099/0022-1317-83-5-979

60. Mueller B, Maerz A, Doberstein K, Finsterbusch T, Mankertz A. Gene expression of the human torque teno virus isolate P/1C1. Virology. (2008) 381:36-45. doi: 10.1016/j.virol.2008.08.017

61. Ott C, Duret L, Chemin I, Trepo C, Mandrand B, Komurian-Pradel F. Use of a TT virus ORF1 recombinant protein to detect antiTT virus antibodies in human sera. J Gen Virol. (2000) 81:294958. doi: 10.1099/0022-1317-81-12-2949

62. Mankotia DS, Irshad M. Cloning and expression of N22 region of Torque Teno virus (TTV) genome and use of peptide in developing immunoassay for TTV antibodies. Virol J. (2014) 11:96. doi: 10.1186/1743-422X-11-96

63. Mankotia DS, Irshad M. Development of an immunoassay for detection of torque teno virus (TTV) Antibodies Using the N22 Expression Product from TTV Genotype 2. Intervirology. (2017) 60:207-16. doi: 10.1159/000487481

64. Goto K, Sugiyama K, Ando T, Mizutani F, Terabe K, Tanaka K, et al. Detection rates of TT virus DNA in serum of umbilical cord blood, breast milk and saliva. Tohoku J Exp Med. (2000) 191:203-7. doi: 10.1620/tjem.191.203

65. Gerner P, Oettinger R, Gerner W, Falbrede J, Wirth S. Motherto-infant transmission of TT virus: prevalence, extent and mechanism of vertical transmission. Pediatr Infect Dis J. (2000) 19:1074-7. doi: 10.1097/00006454-200011000-00009

66. Inami $\mathrm{T}$, Konomi $\mathrm{N}$, Arakawa $\mathrm{Y}$, Abe K. High prevalence of $\mathrm{TT}$ virus DNA in human saliva and semen. J Clin Microbiol. (2000) 38:24078. doi: 10.1128/JCM.38.6.2407-2408.2000

67. Deng $\mathrm{X}$, Terunuma H, Handema R, Sakamoto M, Kitamura T, Ito $\mathrm{M}$, et al. Higher prevalence and viral load of $\mathrm{TT}$ virus in saliva than in the corresponding serum: another possible transmission route and replication site of TT virus. J Med Virol. (2000) 62:531-7. doi: 10.1002/1096-9071(200012)62:4<531::AID-JMV20>3.0.CO;2-C

Conflict of Interest: The authors declare that the research was conducted in the absence of any commercial or financial relationships that could be construed as a potential conflict of interest.

Publisher's Note: All claims expressed in this article are solely those of the authors and do not necessarily represent those of their affiliated organizations, or those of the publisher, the editors and the reviewers. Any product that may be evaluated in this article, or claim that may be made by its manufacturer, is not guaranteed or endorsed by the publisher.

Copyright (C) 2022 Desingu, Nagarajan and Dhama. This is an open-access article distributed under the terms of the Creative Commons Attribution License (CC BY). The use, distribution or reproduction in other forums is permitted, provided the original author(s) and the copyright owner(s) are credited and that the original publication in this journal is cited, in accordance with accepted academic practice. No use, distribution or reproduction is permitted which does not comply with these terms. 